\title{
Compliance of Egyptian Mothers to Asthma Controllers
}

Tareq Hamed Attia ${ }^{1}$, Mohamed Ahmed Arafa ${ }^{1}$, and Khalid Amer Mesbah ${ }^{{ }^{*}}$

${ }^{1}$ Pediatric Department, Faculty of Medicine, Zagazig University

Corresponding author:

Dr. Khalid Amer Mesbah $\mathrm{MBBCH}$

Faculty of Medicine, Tripoli University, Libya.

Resident of Pediatrics, Faculty of Medicine, Zagazig University.

Khalid.mesbah.1982@gmail.com

Submit date: 12-03-2019

Revise date: 06-06-2019

Accept date: 09-06-2019

\section{ABSTRACT}

Background: Objectives include evaluation of compliance of asthmatic children and their mothers through assessment of mother's knowledge, attitude, practices and behavior regarding bronchial asthma and its management at Pediatric Outpatient Clinic at Zagazig University Hospitals. Methods: A crosssectional study was conducted during the period from April 2018 to January 2019 at Pediatric Outpatient Clinic at Zagazig university Hospitals. The study included 137 mothers of asthmatic children. Data were collected by detailed History, full examination, PFTs (Pulmonary function tests) and a structured interview questionnaire included: demographic data of the mothers and their asthmatic children, Assessment of asthma triggers, Asthma Knowledge Questionnaire, Modified Asthma Self-Management Questionnaire, and Morisky Medication Adherence Scale. Results: stress, cold illness, pesticides, air pollution, sports, clutter, and Gasoline were the most common asthma triggers in the present study. Only $37.2 \%$ of the studied mothers had adequate knowledge about asthma. Rural residents, mothers with high education and working mother had significantly more adequate knowledge about asthma. Compliance among the studied mothers was not satisfactory as only $32.1 \%$ of them had adequate compliance. Urban residents, mothers with secondary education and housewives had significantly more adequate compliance. Mothers of children with moderate to severe asthma had significantly higher compliance level. Less absenteeism was associated with adequate compliance of mothers. There was a statistical significant positive correlation between children compliance score and disease duration. There were statistical significant negative correlations between total knowledge and Selfmanagement scores. Conclusion: In the present study, there were lack of asthma self-management ,knowledge and compliance. stress, cold illness, pesticides, air pollution, sports, clutter, and Gasoline were the most common asthma triggers in the present study.

Keywords: Asthma, children, Egyptian mothers, knowledge, compliance.

\section{INTRODUCTION}

A sthma is a major public health problem worldwide with wide differences in prevalence and severity throughout the world. The prevalence of asthma among children has notably increased during the last two decades. It is estimated that bronchial asthma affects over 300 million people, and with a frequency of $7.7 \%$ up to $15 \%{ }^{11-2]}$. In the Middle East, asthma prevalence (ranges 5-23\%) has 
previously been reported to be lower than in developed countries [3]. In Egypt, many studies were done on prevalence of asthma. It ranged from $6.2 \%$ in Upper Egypt to $46.1 \%$ in Cairo ${ }^{[4-5]}$. The pathogenesis of asthma is complex and results from interactions of both environmental and genetic factors which interact resulting in airway inflammation and limiting the bronchial airflow which leads to functional and structural changes in the airways in the form of bronchoconstriction, airway hyper-responsiveness, mucosal edema, mucus plugs formation and finally airways remodeling. However, asthma pathogenesis is not completely understood ${ }^{[6]}$.

In general, the treatment lines of asthma is categorized into two subgroups; rescue medication which aim to quickly relief acute symptoms and distress in the situation of acute asthmatic attack through immediate bronchodilator and suppressing the acute inflammatory process. Rescue medications include short acting beta 2 agonists (SABA), anticholinergic, aminophylline and short course oral steroids. The second group is the controller medication which target reducing the underlining inflammatory process. This group includes corticosteroids, long acting beta 2 agonists (LABA) and leukotriene modifying agents. Patient and family education about the disease's nature, risk factor and self-management play a crucial role in asthma management ${ }^{[7]}$.

Compliance, describes the degree of which a patient takes medication as it has been prescribed. Compliance has largely been replaced by the term "adherence" which has fewer negative connotations. It has been argued that both terms reflect a paternalistic model of care rather than a partnership. However, the alternative "concordance", which has been coined to reflect a therapeutic decision that incorporates the common goals of the physician and patient has not been widely accepted ${ }^{[8-9]}$.

Compliance with therapeutic regimens in bronchial asthma, particularly in children, is low. Education is the cornerstone for asthma management and has been recommended by national and international guidelines. Additionally, it has been cited as an essential component of any asthma management strategy, by improving asthma knowledge and changing behavior. Recently there is little awareness about asthma in most of the developing countries ${ }^{[10-11]}$.

Parents of children with asthma frequently have poor understanding of the disease and its management, and this may contribute to the need for hospitalization [1213]. Alert parents can identify the problem of their child, and accurate symptoms perception is a critical component of asthma management and control ${ }^{[14]}$.

Asthma education for children and their mothers is essential to control asthma.The purpose of asthma education is to help the patient and their caregivers to develop the knowledge and skills to know when asthma is worsening, to take appropriate action and to be motivated to avoid triggers and adhere to the management regimen ${ }^{[15]}$.

The family members of a child with asthma should have a clear understanding of nature of asthma, possible aggravating factors, the mechanism of action, mode of administration, and possible side effects of the medications used. They should be provided with written instructions regarding the administration of medications during acute asthma episodes and must be familiar with the signs of deteriorating control indicating there is need for urgent medical attention. As children with asthma approach adolescence, they should be encouraged to take increasing responsibility for their own care ${ }^{[16]}$.

Since asthma is such a common disease, it has received wide public health attention. Attention has been devoted to not only search for the factors working together in the development of asthma, but also to psychological, social and financial aspects of the illness. Therefore, the rationale of the present study will be conducted to evaluate the compliance of asthmatic children and their mothers through assessment of their knowledge, attitude, behavior and practices regarding bronchial asthma and its management.

\section{METHODS}

This study is a cross sectional study that was carried on at Outpatient Clinic of 
Pediatric Department, Zagazig University Hospitals from April 2018 to January 2019. The study included randomly selected 137 mothers of asthmatic children attended to Pediatric Outpatient Clinic at Zagazig university Hospitals with the following criteria: Inclusion criteria: - Age of the asthmatic children ranged from 2 to 12 years old, Known asthmatic children for at least one year and Mothers giving informed consent. Exclusion criteria: - Children not living with their mothers, Children presented to the outpatient clinic with other relatives (not mother) and Children wheezing from other causes.

Patients were subjected to a structured interview questionnaire after detailed history, full examination and PFTs (Pulmonary function tests). Questionnaire was written in a simple Arabic language after translation using back translation technique. It included 5 parts: First part was demographic data of the mothers and their asthmatic children: Age, sex, residence, duration of disease (years), school absenteeism, education and occupation of mother. Second part was assessment of asthma triggers by using the Asthma Trigger Inventory (ATI) ${ }^{[17]}$. The ATI consists of 31item self-report inventory. The ATI has adequate internal consistency reliability with Cronbach's alpha ranging from 0.81 to 0.94 , it was translated into Arabic language using back translation technique. Third part was assessment of knowledge by using Asthma Knowledge Questionnaire (AKQ). Arabic version of AKQ was adopted from Alreshidi (2015) ${ }^{[18]}$, who adapted the English version from (Al-Motlaq and Sellick, 2011) ${ }^{[19]}$. The instrument consists of 24 questions (23 true/false items and one open-ended question) including: general data about asthma, triggers, symptoms, and asthma treatment and management. The domains of the AKQ are well constructed with evidence of construct and discriminate validity, high internal consistency of items and test-retest reliability. Forth part was assessment of asthma selfmanagement by using Asthma SelfManagement Questionnaire (ASMQ) ${ }^{[20]}$.

ASMQ measures management using preventive strategies, inhaler use, differences between maintenance and rescue medications, and use of peak flow meters. It was translated into Arabic language using back translation technique. Fifth part was assessment of medication adherence by using Morisky adherence scale which is an 8-item questionnaire, and which is a valid measure of self-reported adherence will measure medication adherence. It was translated into Arabic language using back translation technique ${ }^{[21]}$.

\section{Pilot study}

Pilot study was done one month before data collection to detect any difficulties and to test content validity and reliability of the questionnaire after Arabic translation. It also helped to estimate time needed for data collection and expected frequency. The mothers, included in the pilot study were excluded from the main sample because of the changes that were done in the final version of the questionnaire.

\section{Data management}

1. Scoring of Asthma Knowledge Questionnaire (AKQ): The total score of knowledge was 27 degree, the first score will be given for each correct answer and zero for incorrect answer for each area of knowledge, the scores of the questions were summed-up and the total score divided by the number of the items. These scores were converted into a percent score. The total knowledge was considered satisfactory if the percent score was $60 \%$ or more and unsatisfactory if less than $60 \%{ }^{[18-19]}$.

2. Scoring of Modified Asthma SelfManagement Questionnaire (ASMQ): The ASMQ is a 15-item multiple-choice questionnaire that measures selfmanagement strategies for asthma. There was only one correct response and total scores range from 0 to 15 . A score of 0 to 100 is calculated, with higher scores indicating higher knowledge of asthma self-management. The score was obtained by this formula (raw score/15) x 100 . Construct validity was established and adequate internal consistency and reliability has been demonstrated with a Cronbach $\alpha$ of $0.71^{[20]}$. 
3. Scoring of Morisky Medication Adherence Scale: It is an 8-item questionnaire, total scores range from 0 to 4 , where 0 indicates high adherence, and 4 indicates nonadherence. A score of " 0 " was classified as "high adherence"; scores from 1 to 2 were classified as "medium adherence"; and scores greater than 2 (3-8) were classified as "low adherence". This instrument had adequate internal consistency reliability with a Cronbach alpha coefficient of 0.80 and concurrent and predictive validity has been established ${ }^{[21]}$.

4. Statistical analysis: The collected data was entered and analyzed by computer using Statistical Package of Social Services, version 25 (SPSS) ${ }^{\text {[22] }}$.

Results were presented by tables and graphs. Quantitative data was presented as mean and standard deviation. Qualitative data was presented as frequencies and proportions.

Pearson Chi square test $\left(\chi^{2}\right)$ was used to analyze qualitative independent data. Pearson's correlation confident (r) was used to analyze linear association between continuous variables. In all the tests, $\mathrm{p}$ value of $\leq 0.05$ was taken as significant ${ }^{\text {[23] }}$.

\section{Administrative design and Ethical considerations}

- Approval of Institutional Review Board (IRB) of Zagazig University, Faculty of medicine was taken after revision of study protocol.

- An official permission from Zagazig University, Faculty of medicine was taken to Pediatric Department. Zagazig university Hospital was informed about the nature and steps of the study and written consent was taken from institutional managers.

- The study participants were informed about the nature and the purpose of the study and verbal consent was taken before interview.

- All patient's data were confidential.

\section{RESULTS}

Regarding socio-demographic characteristics of the studied patients, median age was 6.0 years old. Almost half of the studied patients were males. Median duration of disease was 4.0 years. Median absence day was 3.0 days. Two thirds of the studied patients were rural residents. Almost half of mothers had basic education. Two thirds of mothers were housewives (Table 1). Child asthma severity was mild in $36.4 \%$ of the studied patients, while it was severe in $8.7 \%$ only of the studied patient (Table 2). There was a statistical significant association between asthma severity and absenteeism. Moderate and severe asthma had significantly higher absenteeism duration.

Regarding asthma triggers among the studied patients, stress, cold illness, pesticides, air pollution, sports, clutter and Gasoline were the most common triggers in the present study (Table 3). Regarding knowledge assessment among the studied mothers, only $37.2 \%$ of them had adequate knowledge about asthma (Table 4).There were statistical significant associations between mother's knowledge level and some socio-economic characteristics of the studied mothers. Rural residents, mothers with high education and working mother had significantly more adequate knowledge about asthma (Table 5). Regarding asthma selfmanagement and compliance among the studied mothers, mean scores were 26.9 \& 33.3 respectively (Table 4). There were statistical significant associations between mother's compliance level and some socioeconomic characteristics of the studied mothers. Urban residents, mothers with secondary education and housewives and had significantly more adequate compliance (Table 6). Mothers of children with moderate to severe asthma had significantly higher compliance level. There was a statistical significant positive correlation between mother's compliance score and disease duration. There were statistical significant negative correlations between total knowledge and Self-management scores (Table 7). 
Table 1. Socio-demographic distribution among studied group:

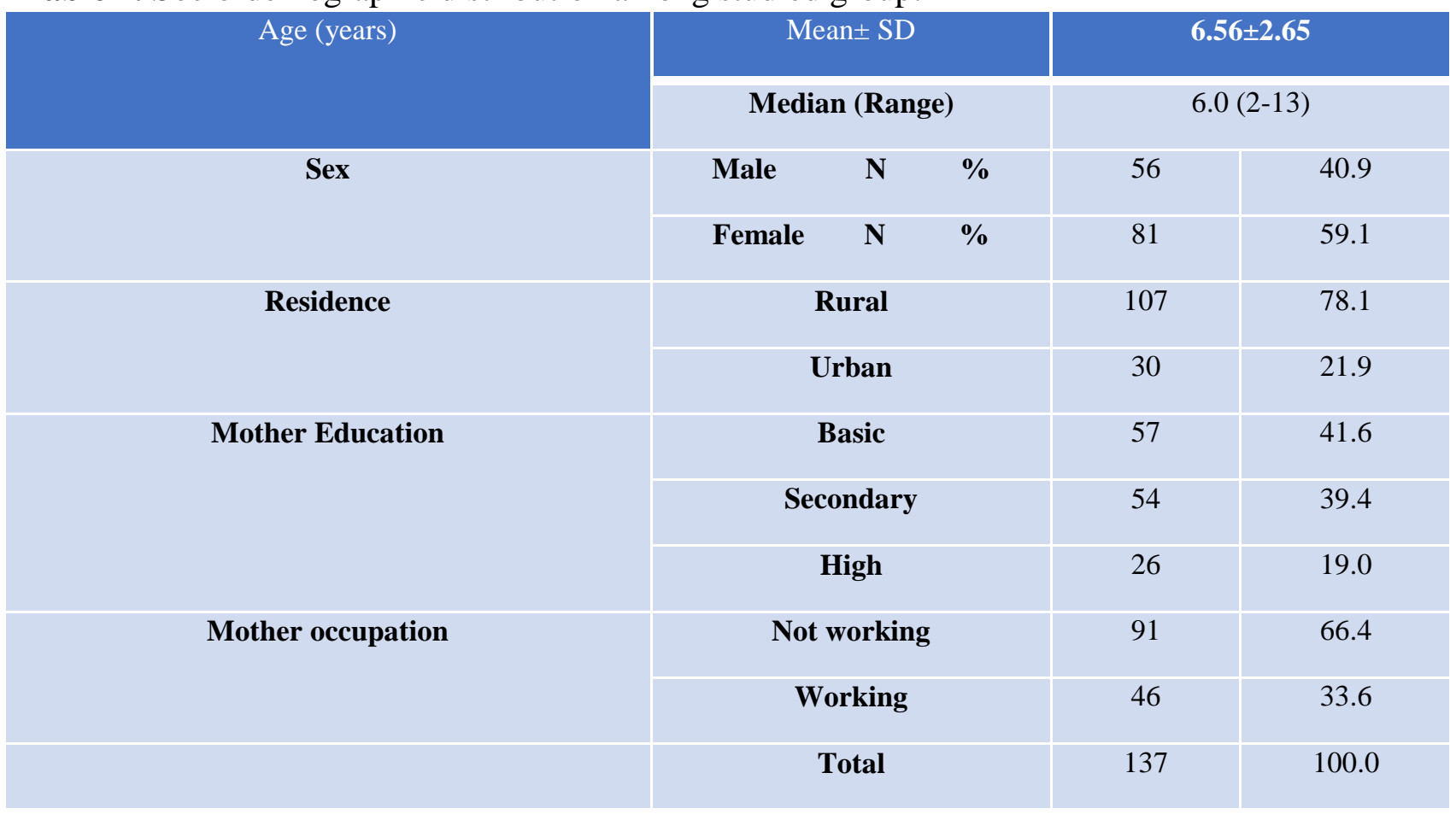

Table 2. Asthma history and examination among studied group:

\begin{tabular}{|c|c|c|c|}
\hline Duration of disease(years) & Mean \pm SD & \multicolumn{2}{|c|}{$3.78 \pm 2.22$} \\
\hline & $\begin{array}{l}\text { Median } \\
\text { (Range) }\end{array}$ & \multicolumn{2}{|c|}{$4.0(1-12)$} \\
\hline \multirow[t]{2}{*}{ Absence day } & Mean \pm SD & \multicolumn{2}{|c|}{$1.98 \pm 1.2$} \\
\hline & $\begin{array}{l}\text { Median } \\
\text { (Range) }\end{array}$ & \multicolumn{2}{|c|}{$3.0(0-4)$} \\
\hline \multirow[t]{5}{*}{ Child asthma severity calculated according to age } & Intermittent & 35 & 25.5 \\
\hline & Mild & 50 & 36.4 \\
\hline & Moderate & 40 & 29.1 \\
\hline & Sever & 12 & 8.7 \\
\hline & Total & 137 & 100.0 \\
\hline
\end{tabular}


Table 3. Asthma triggers distribution among studied group:

\begin{tabular}{|c|c|c|}
\hline \multirow[t]{2}{*}{ Triggers } & \multicolumn{2}{|c|}{$+\mathrm{VE}$} \\
\hline & $\mathbf{N}$ & $\%$ \\
\hline Stress & 135 & 98.5 \\
\hline Cold or respiratory illness & 130 & 94.9 \\
\hline Pesticides & 129 & 94.2 \\
\hline Air pollution & 129 & 94.2 \\
\hline Sports & 129 & 94.2 \\
\hline Clutter & 129 & 94.2 \\
\hline Gasoline & 128 & 93.4 \\
\hline Flu & 122 & 89.1 \\
\hline Pollen & 120 & 87.6 \\
\hline Paint or varnish & 119 & 86.9 \\
\hline Emotional upsets & 118 & 86.1 \\
\hline Open fire place & 114 & 83.2 \\
\hline Gas stove & 107 & 78.1 \\
\hline Chalk & 105 & 76.6 \\
\hline Foods & 93 & 67.9 \\
\hline Mold & 88 & 64.2 \\
\hline Burning wood & 88 & 64.2 \\
\hline Change in weather & 88 & 64.2 \\
\hline Pets dander & 78 & 56.9 \\
\hline Dust mites & 71 & 51.8 \\
\hline Mildew & 60 & 43.8 \\
\hline Moisture & 60 & 43.8 \\
\hline Seasonal & 56 & 40.9 \\
\hline Drugs & 52 & 38.0 \\
\hline Strong smells or perfume & 41 & 29.9 \\
\hline Flowers & 23 & 16.8 \\
\hline Passive smoking & 15 & 10.9 \\
\hline Pets & 9 & 6.6 \\
\hline Cockroaches & 9 & 6.6 \\
\hline Grass & 7 & 5.1 \\
\hline
\end{tabular}

Table 4. Asthma self-management and total compliance score distribution among studied group:

\begin{tabular}{|c|c|c|c|}
\hline Score: & Total knowledge & Asthma self-management (\%) & Compliance (\%) \\
\hline Mean \pm SD & $13.1 \pm 2.5$ & $26.91 \pm 8.98$ & $33.3 \pm 12.5$ \\
Median (Range) & $13(7-18)$ & $25.0 \%(12.5 \%-50.0 \%)$ & $38.5(0.0 \%-87.0 \%)$ \\
\hline $\begin{array}{c}\text { Level, n (\%): } \\
\text { Adequate }\end{array}$ & $51(37.2 \%)$ & $50(36.5 \%)$ & $44(32.1 \%)$ \\
Inadequate & $86(62.8 \%)$ & $87(63.5 \%)$ & $93(68.9 \%)$ \\
\hline
\end{tabular}


Table 5. Relation between adequate knowledge and socio-demographic data:

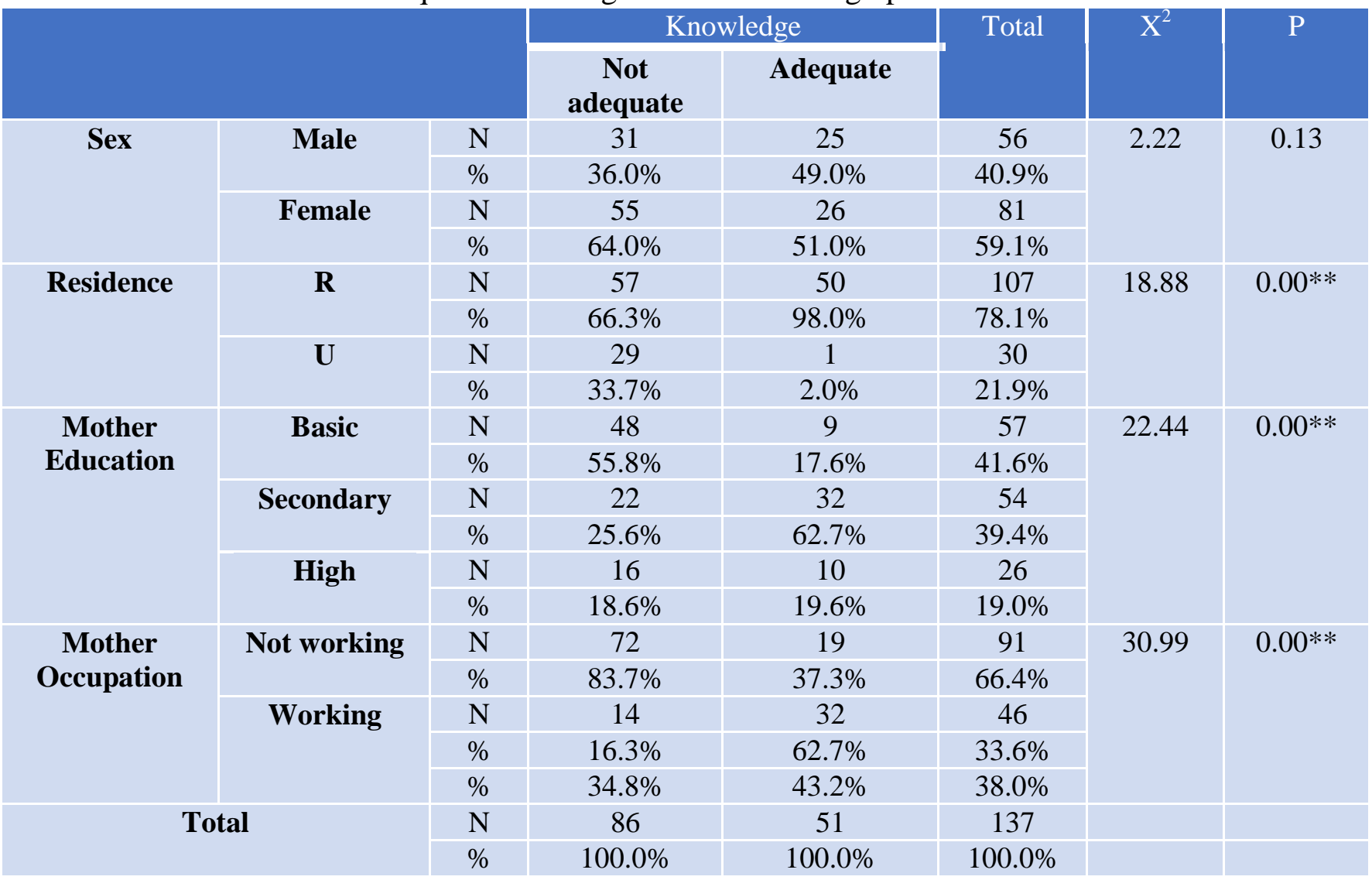

Table 6. Relation between adequate compliance and socio-demographic data:

\begin{tabular}{|c|c|c|c|c|c|c|c|}
\hline & \multicolumn{2}{|c|}{ Compliance } & \multirow[t]{2}{*}{ Total } & \multirow[t]{2}{*}{$\mathrm{X}^{2}$} & \multirow[t]{2}{*}{$\mathrm{P}$} \\
\hline & & & Adequate & $\begin{array}{c}\text { Not } \\
\text { adequate }\end{array}$ & & & \\
\hline \multirow[t]{4}{*}{ Sex } & \multirow[t]{2}{*}{ Male } & $\mathbf{N}$ & 15 & 41 & 56 & \multirow[t]{4}{*}{1.23} & \multirow[t]{4}{*}{0.26} \\
\hline & & $\%$ & $34.1 \%$ & $44.1 \%$ & $40.9 \%$ & & \\
\hline & \multirow[t]{2}{*}{ Female } & $\mathbf{N}$ & 29 & 52 & 81 & & \\
\hline & & $\%$ & $65.9 \%$ & $55.9 \%$ & $59.1 \%$ & & \\
\hline \multirow[t]{4}{*}{ Residence } & \multirow[t]{2}{*}{$\mathbf{R}$} & $\mathbf{N}$ & 22 & 85 & 107 & \multirow[t]{4}{*}{29.93} & \multirow[t]{4}{*}{$0.00 * *$} \\
\hline & & $\%$ & $50.0 \%$ & $91.4 \%$ & $78.1 \%$ & & \\
\hline & \multirow[t]{2}{*}{$\mathbf{U}$} & $\mathbf{N}$ & 22 & 8 & 30 & & \\
\hline & & $\%$ & $50.0 \%$ & $8.6 \%$ & $21.9 \%$ & & \\
\hline \multirow[t]{6}{*}{ Mother Education } & \multirow[t]{2}{*}{ Basic } & $\mathbf{N}$ & 22 & 35 & 57 & \multirow[t]{6}{*}{15.24} & \multirow[t]{6}{*}{$0.00 * *$} \\
\hline & & $\%$ & $50.0 \%$ & $37.6 \%$ & $41.6 \%$ & & \\
\hline & \multirow[t]{2}{*}{ Secondary } & $\mathbf{N}$ & 22 & 32 & 54 & & \\
\hline & & $\%$ & $50.0 \%$ & $34.4 \%$ & $39.4 \%$ & & \\
\hline & \multirow[t]{2}{*}{ High } & $\mathbf{N}$ & 0 & 26 & 26 & & \\
\hline & & $\%$ & $0.0 \%$ & $28.0 \%$ & $19.0 \%$ & & \\
\hline \multirow{5}{*}{$\begin{array}{l}\text { Mother } \\
\text { Occupation }\end{array}$} & \multirow{2}{*}{$\begin{array}{c}\text { Not } \\
\text { working }\end{array}$} & $\mathbf{N}$ & 37 & 54 & 91 & \multirow[t]{5}{*}{9.07} & \multirow[t]{5}{*}{$0.003 *$} \\
\hline & & $\%$ & $84.1 \%$ & $58.1 \%$ & $66.4 \%$ & & \\
\hline & \multirow[t]{3}{*}{ Working } & $\mathbf{N}$ & 7 & 39 & 46 & & \\
\hline & & $\%$ & $15.9 \%$ & $41.9 \%$ & $33.6 \%$ & & \\
\hline & & $\%$ & $36.4 \%$ & $74.2 \%$ & $62.0 \%$ & & \\
\hline \multirow{2}{*}{\multicolumn{2}{|c|}{ Total }} & $\mathbf{N}$ & 44 & 93 & 137 & & \\
\hline & & $\%$ & $100.0 \%$ & $100.0 \%$ & $100.0 \%$ & & \\
\hline
\end{tabular}


Table 7. Correlation among different score and age and duration of disease:

\begin{tabular}{|c|c|c|c|c|}
\hline & & Total knowledge & $\begin{array}{c}\text { Self-management } \\
\text { percentage score }\end{array}$ & $\begin{array}{c}\text { Compliance } \\
\text { percentage }\end{array}$ \\
\hline Age (years) & $\mathrm{r}$ & 0.076 & 0.209 & 0.111 \\
\hline Disease duration (years) & $\mathrm{P}$ & 0.379 & 0.057 & 0.998 \\
& $\mathrm{r}$ & 0.139 & -0.007 & $0.382^{* *}$ \\
\hline Absenteeism days & $\mathrm{P}$ & 0.105 & .934 & .000 \\
\hline Asthma severity & $\mathrm{r}$ & $-0.35^{*}$ & $-0.41^{* *}$ & $-0.27^{*}$ \\
\hline \multirow{2}{*}{ Self-management } & $\mathrm{P}$ & 0.002 & $<0.001$ & 0.01 \\
\hline percentage score & $\mathrm{r}$ & 0.14 & 0.15 & $0.42^{* *}$ \\
\hline Compliance percentage & $\mathrm{P}$ & 0.34 & 0.26 & $<0.001$ \\
\hline & $\mathrm{P}$ & $-.178^{*}$ & - & $.189^{*}$ \\
\hline & $\mathrm{P}$ & .037 & - & .027 \\
\hline
\end{tabular}

\section{DISCUSSION}

This study aimed to evaluate the compliance of asthmatic children and their mothers through assessment for their knowledge, attitude, practices and behaviors regarding bronchial asthma and its management. Regarding asthma triggers among the studied patients, stress, cold illness, pesticides, air pollution, sports, clutter, and Gasoline were the most common triggers in the present study. In a study conducted at Zagazig city, Mersal \& ElAwady ${ }^{[24]}$ found that, the most common triggers were: cold and flu, exhausting fumes, cigarette smoke, running, being angry, feeling unhappy, and feathers from birds. In Ritz et al., [25] physical activity, plant-related allergens, air pollution/irritants, infections, animal allergens, climate related triggers and house dust were the most common triggers. While in Stridsman et al ${ }^{[26]}$, poor air quality, poorly cleaned environment, allergens, strong fragrance, rebuilding projects, physical education and stress were the most common triggers.

Regarding knowledge assessment among the studied mothers, only $37.2 \%$ of them had adequate knowledge about asthma. There were statistical significant associations between mother's knowledge level and some socio-economic characteristics of the studied mothers. Rural residents, mothers with high education and working mothers had significantly more adequate knowledge about asthma. Similar to the present study, McCorkle ${ }^{[27]}$ and Mersal \& El-Awady ${ }^{[24]}$ found that knowledge level increased in mothers of elder children. Also, Abdalla ${ }^{[28]}$ concluded that the higher the level of education of mothers leads to increase in knowledge of symptoms. On other hand the same study found no association between mother's occupation and knowledge level. In agreement with the present study, Coelho et al., ${ }^{[11]}$ confirmed that majority of the mothers had unsatisfactory knowledge about asthma. The relief and maintenance treatment were the most unknown issues in their sample. Additionally, observed was an extreme presence of beliefs in popular myths that interfered with disease understanding. Regarding asthma self-management among the studied mothers, mean score was $26.9 \%$. This finding was consistent with that of McCorkle ${ }^{[27]}$ and Mersal \& El-Awady ${ }^{[24]}$ who found that nearly three quarters of participants had inadequate asthma management .

Compliance is understood as patient's behaviors (in terms of taking medication, following diets or executing life style changes) coinciding with healthcare provider's recommendations for health and medical advice ${ }^{[29]}$. In the present study, 
compliance among the studied mothers was not satisfactory as only $32.1 \%$ of them had adequate compliance.

Non-compliance is said to occur when patients deviate from the prescribed instructions given by a healthcare professional. The objective of any medical therapy is to achieve certain desired outcomes. The result however depends largely on patient related factors and despite the efforts of the healthcare professionals, the desired outcomes might not be achieved if the patients are non-compliant. In the present study, there were statistical significant associations between mother's compliance level and some socio-economic characteristics of the studied mothers. Urban residents, mothers with secondary education and housewives and had significantly more adequate compliance. Mothers of children with moderate to severe asthma had significantly higher compliance level.

In agreement with the present study, Mersal \& El-Awady ${ }^{[24]}$ concluded that three quarters of children with asthma had low adherence to asthma medications. In addition, McCorkle ${ }^{[27]}$ and Baiardini et al. [30] revealed that socioeconomic status and level of education markedly influences the way in which patients take their treatment. On the other hand, Singh et al. concluded that $47 \%$ of patients were compliant ${ }^{[31]}$. Compliance was associated with asthma severity while mother's education did not have any influence on the compliance. Against the present study, DiMetteo [32] stated that even patients with high educational qualifications may not comprehend the benefits and necessity of adhering to treatment.

Regarding correlation among different scores, there were statistical significant negative correlations between total knowledge score and Self-management score. It can be explained by that patients are passive about the treatment and need education about the disease, encouragement to ask questions and overall listening and appreciating the patient's opinion about the disease. However there was a statistical positive correlation between total knowledge score and compliance score.
Health education about asthma typically begins in the physician's office. This education is usually directed at the parents more than the child and consists of a brief review of asthma and the medication prescribed for its management ${ }^{[33]}$. In Sin et al., [34] asthma knowledge had significant positive relationships with asthma selfmanagement behaviors and accounted for $14 \%$ of self-management behaviors variability. In addition, Singh et al. ${ }^{[31]}$ found that compliance was affected by total knowledge score.

\section{CONCLUSION}

In the present study, there were lack of asthma self-management knowledge and compliance. stress, cold illness, pesticides, air pollution, sports, clutter, and Gasoline were the most common asthma triggers in the present study.

\section{RECOMMENDATIONS}

In the light of this study, it is recommended to improve awareness of the parents of asthmatic children by intensive educational programs. Also, written guidelines should be issued to parents to initiate treatment of their children at emergencies. Implementation of Selfmanagement programs for children with asthma can enable them to learn more about their asthma and feel better about their capability to manage their own symptoms. Conduct this study on wider scale of children in the future.

\section{Acknowledgements}

The authors wish to acknowledge the valuable contribution of the children and mothers who participating in the study, and the support and opportunity from the Zagazig Medical University.

\section{Declaration of interest}

The authors report no conflicts of interest. The authors alone are responsible for the content and writing of the paper.

Funding information None declared

\section{REFERENCES}

1. Masoli M, Fabian D, Holt S, Beasley R. The global burden of asthma: executive summary of the GINA Dissemination Committee report. Allergy. 2004 May; 59(5): 469-478.

2. CDC National Center for Health Statistics. Asthma Prevalence, Health Care 
Use and Mortality: United States, 200305. [cited]; Available from: http://www.cdc.gov/nchs/products/pubs/pubd /hestats/ashtma03-05/asthma03-05.htm\#fig1.

3. El-Sharif N, Abdeen Z, Qasrawi R, Moens $G$ and Nemery B. Asthma prevalence in children living in villages, cities and refugee camps in Palestine. European respiratory journal. 2002; 19(6): 1026-1034.

4. Abdallah AM, Sanusy KA, Said WS, Mahran DG and Mohamed-Hussein AA. Epidemiology of bronchial asthma among preparatory school children in Assiut district. Egyptian Journal of Pediatric Allergy and Immunology. 2012; 10(2).

5. Al Dhduh MA, Sabri NA and Fouda EM. Prevalence and severity of allergic diseases among Egyptian pediatric indifferent Egyptian areas. Int J Pharm Sci Res. 2015; 2: 107.

6. Goksör E, Alm B, Thengilsdottir H, Pettersson R, Åberg N and Wennergren G. Preschool wheeze-impact of early fish introduction and neonatal antibiotics. Acta Paediatrica. 2011; 100(12): 1561-1566.

7. Najafizadeh K, Pour HS, Ghadyanee M, Shiehmorteza M, Jamali $M$ and Majdzadeh S. A randomised, double-blind, placebo-controlled study to evaluate the role of formoterol in the management of acute asthma. Emergency Medicine Journal. 2007; 24(5): 317-321.

8. Horne R. Compliance, adherence, and concordance: implications for asthma treatment. Chest. 2006; 130(1): 65S-72S.

9. Dima AL, de Bruin M and Van Ganse E. Mapping the asthma care process: implications for research and practice. The Journal of Allergy and Clinical Immunology: In Practice. 2016; 4(5): 868-876.

10. Gajanan G, Padbidri VS, Chaudhury A. Assessment of Knowledge and Attitude of Parents towards the Allergy and Bronchial Asthma in Their Children. International Journal of Medicine and Public Health. 2016; 6(3): 121-125.

11. Coelho ACC, de Souza-Machado $C$, de Oliveira TS, dos Santos TN N, Cruz ÁA and Souza-Machado A. Curricular intervention increases adolescents' knowledge about asthma: a randomized trial. Jornal de Pediatria (VersãoemPortuguês). 2018; 94(3): 325-334.

12. Cane RS, Ranganathan SC, and Mckenzie SA. What do parent of wheezy children understand by wheeze? Arch Dis Child. 2000; 82:327-332.

13. Young B, Fitch GE, Dixon-Woods M, Lambert PC and Brooke AM. Parents accounts of wheeze and asthma related symptoms: a qualitative study. Archives of disease in childhood. 2002; 87(2): 131-134.

14. Yoos HL, Kitzman H, McMullen $A$ and Sidora K. Symptom perception in childhood asthma: how accurate are children and their parents?. Journal of Asthma. 2003); 40(1): 27-39.

15. Maridee A. Asthma Self-Management Patient Education. Respiratory Care. 2008; 53(6): 603-607.

16. Earle B and Weiss MD. Bronchial Asthma Mechanism and Therapeutics. 3rd ed.New York: Little Brown Company. (1993). p 1113.

17. Ritz T, Steptoe A, Bobb C, Harris AH and Edwards M. The asthma trigger inventory: validation of a questionnaire for perceived triggers of asthma. Psychosomatic Medicine. 2006; 68(6): 956-965.

18. Alreshidi NM. The impact of a schoolbased, nurse-delivered asthma health education programme on quality of life, knowledge and attitudes of Saudi children with asthma (Doctoral dissertation, University of Salford) (2015).

19. Al-Motlaq M and Sellick K. Development and validation of an asthma knowledge test for children 8-10 years of age. Child: Care, health and development. 2011; 37(1): 123128.

20. Mancuso CA, Sayles W and Allegrante JP. Development and testing of the asthma selfmanagement questionnaire. Annals of Allergy, Asthma \& Immunology. 2009; 102(4): 294-302.

21. Morisky DE, Ang A, Krousel-Wood M, Ward HJ. Predictive validity of a medication adherence measure in an outpatient setting. Journal of Clinical Hypertension. 2008; 10(5): 348-354.

22. IBM. IBM SPSS Statistics for Windows, Version 25. Armonk, NY: IBM Corp. (2017). http://www-

01.ibm.com/support/docview.wss?uid=swg2 7049428

23. Petrie A and Sabin C. Medical Statistics at a Glance (3rd edition, Vol.23). WileyBlackwell. (2009). https://doi.org/10.1017/CBO9781107415324. 004. 
24. Mersal FA and El-Awady S. Evaluation of bronchial asthma educational package on asthma self-management among school age children based on Orem's self-care model in Zagazig city. 2018.

25. Ritz T, Kullowatz A, Kanniess F, Dahme B and Magnussen $\mathbf{H}$. Perceived triggers of asthma: evaluation of a German version of the Asthma Trigger Inventory. Respiratory medicine. 2008; 102(3): 390-398.

26. Stridsman C, Dahlberg E, Zandrén $K$ and Hedman L. Asthma in adolescence affects daily life and school attendance-Two cross-sectional population-based studies 10 years apart. Nursing open. 2017; 4(3): 143148.

27. McCorkle LS. A study of the relationships of self-efficacy of self-management of asthma and asthma self-management knowledge (Doctoral dissertation, Texas A\&M University). (2005).

28. Abdalla WAMA. Knowledge, Attitude and Practices of Parents of Asthmatic Children about Asthma in Elwehda village in South of Gezira Locality, Gezira State, Sudan (2017) (Doctoral dissertation, University of Gezira). (2017).

29. Bosley CM, Fosbury JA and Cochrane GM. The psychological factors associated with poor compliance with treatment in asthma. European Respiratory Journal. 1995; 8(6): 899-904.

30. Baiardini I, Braido F, Giardini A, Majani G, Cacciola C, Rogaku, et al., Adherence to treatment: assessment of an unmet need in asthma. Journal of Investigational Allergology and Clinical Immunology. 2006; 16(4): 218.

31. Singh RK, Thapar RK, Gupta RK and Abhijit YV. Factors Affecting Drug Compliance in Paediatric Asthma. Journal of Nepal Paediatric Society. 2017; 37(1): 31-35.

32. DiMatteo MR. Patient adherence to pharmacotherapy: the importance of effective communication. Formulary. 1995; 30: 59698.

33. Hannaway PJ. Asthma--an Emerging Epidemic: A Manual for Patients with Asthma, Parents of Children with Asthma, Asthma Educators, Health-care Providers, School Nurses and Coaches. Lighthouse Press. (2002).

34. Sin MK, Kang DH and Weaver $M$. Relationships of asthma knowledge, selfmanagement, and social support in African American adolescents with asthma. International journal of nursing studies. 2005; 42(3): 307-313.

To cite this article: Attia TH, Arafa MA, Mesbah KA. Compliance of Egyptian Mothers to Asthma Controllers. Zumj May. 2020(26) No.3,364-374: 10.21608/zumj.2019.10448.1101. 